\title{
Presentation, Management and Pathogenesis of the SARS-CoV-2 in Children
}

\section{Sam Hassan*}

Associate Professor of Pediatric Medicine, Department of Pediatrics, Mediclinic City

Hospital, Dubai, United Arab Emirates

*Corresponding Author: Sam Hassan, Associate Professor of Pediatric

Medicine, Department of Pediatrics, Mediclinic City Hospital, Dubai, United Arab

Emirates.
Received: April 29, 2020

Published: June 15, 2020

(C) All rights are reserved by Sam Hassan.

\begin{abstract}
Background: The current pandemic due to the novel coronavirus (SARS-Cov-2) (Figure 1) that caused COVID-19 infection is the most prevalent challenge for mankind since the World War II. This is a review article about up-to-date studies of this global significant pandemic.

Methods and Results: Review of current and related researches published online in English language about SARS-CoV-2 particularly in children. For the purpose of the journal citation the references reduced from 119 reviewed articles to 49 references, hence some of the references will be referred to within the text. Until now June 2020, the confirmed cases of infection globally exceeding 8.5 million cases with a mortality rate just above $6 \%$. The confirmed reported cases are not representing the tangible scale of the pandemic due to insufficient testing programs, asymptomatic cases and false negatives following upper respiratory swabs only. The pandemic started with an epicenter in Wuhan city in China and moved like a tsunami to a second epicenter in Europe particularly Italy and Spain before it landed in the United States and the UK and lastly emerged in South America and Africa. Both adults and children are at risk of the disease however the course of the infection is milder in children. Spread of the infection may happen from any infected individual to others. Death were reported more in adults particularly the elderly and patients with preexisted comorbidities. This article is a review of the current studies focusing on the nature of the virus, immunopathology, clinical presentation in children and shading light on management and control.

Conclusion: Children are less likely to show sever SARS-CoV-2 infection with lower mortality rate than adults, most likely due to their immune system. Possible causes are the molecular receptors used by the virus for host cell entry, the crossed immunity against common corona viruses and other causes need more studies. Children show milder, different or asymptomatic course, hence the number may be under-estimated. The overall consequences of the COVID-19 on children is yet to be understood especially in relation to pregnancy, new-born babies, educations, welfare and future. The post COVID-19 complications such as, psychological and mental impacts, respiratory complications and post-viral sequela yet to be identified.

Keywords: COVID-19; SARS-Cov-2; Coronavirus; Children; Novel Coronavirus; 2019-nCoV; HCoV; SARS; MERS
\end{abstract}

\section{Background}

The current pandemic due to the novel coronavirus (SARSCov-2) (Figure 1) that caused COVID-19 infection is the most prevalent challenge for mankind since the World War II. This is a review article about up-to-date studies of this global significant pandemic.

\section{Introduction}

Coronaviruses (CoVs) were originally discovered in 1930 s after acute respiratory infections in chicken. It belongs to a big family called coronaviridae, of enveloped single stranded RNA zoonotic viruses that first identified in humans in 1962 (Br Med J. 


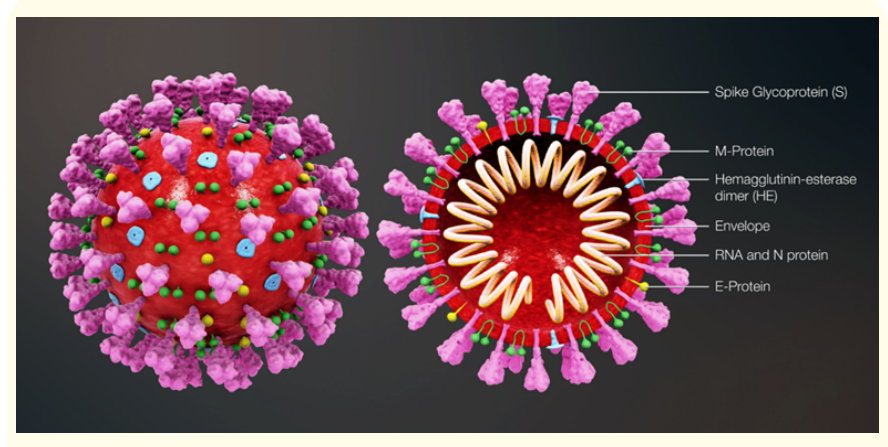

Figure 1: CoV-SARS-2 virus from: WWW.SCIENTIFICANIMATIONS.COM.

1962;14;2(5297):82-86). CoVs causes wide variety of diseases in animals and humans including respiratory, gastrointestinal, hepatic and neurological. Based on genotypic and serological characterization, CoVs divided into 4 main groups namely, Alpha, Beta, Gamma and Delta-coronaviruses (Journal of Virology. 2013;87(12):70397045). Alpha and Beta are predominantly infecting mammals such as bats, civets, rodents, camels and human, while Delta and Gamma infecting birds but some of them can also infect mammals. Before the acute respiratory syndrome (SARS-CoV) epidemic in 2003 only 19 CoVs were known, later more than 20 additional new CoVs were identified (Lancet. 2020;395:514-523). The 4 seasonal common HCoVs are 2 Alpha (HCoV2-229E and HCoV2-NL63) and 2 Beta (HCoV2-HKU1 and HCoV2-OC43). These are commonly circulating among humans causing self-resolving flu like illnesses particularly in winter but also reported in spring and summer and the commonest one effecting children is HCoV2-OC43. HCoVs have also been associated with exacerbations of chronic obstructive pulmonary disease such as cystic fibrosis and asthma. They are found in 4 - 8\% of children admitted due to respiratory infections especially under 3 years of age and with cardiovascular diseases. In contrast to other respiratory tract viruses such as respiratory syncytial virus (RSV) and influenzas viruses, there is no decrease in the relative prevalence of HCoVs infections with advancing age. SARS- CoV, MERS- CoV, NL63 and 229E are considered to have originated in bats while OC43 and HKU1 likely originated from rodents (Nat Rev Microbiol. 2019;17(3):181-192) (Figure 2).

The SARS-CoV, MERS-CoV and the latest SARS-CoV-2 spread as epidemics and associated with high morbidity and mortality. The

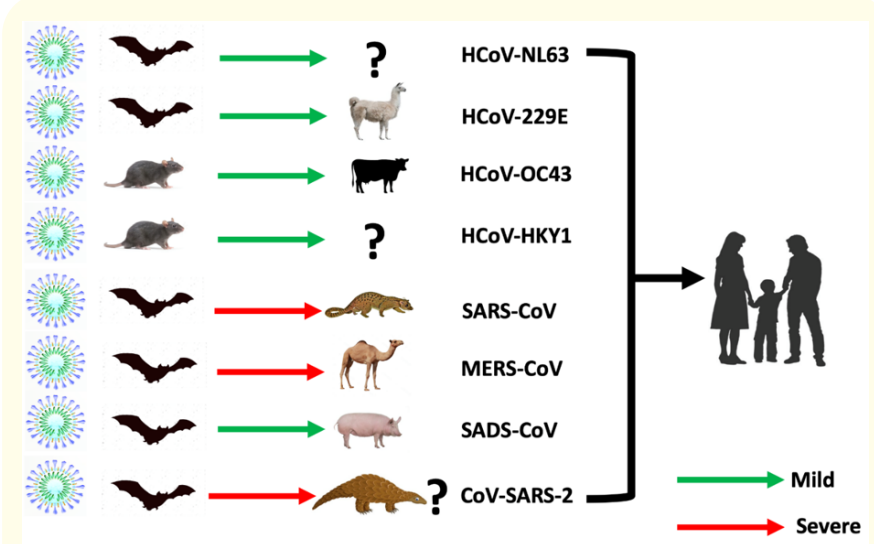

Figure 2: Common and epidemic coronaviruses and their hosts.

SARS-CoV epidemic emerged in China in Guangdong province in 2002 from bats with civets' cats as possible intermediate host. It spread rapidly to Hong Kong then to another 29 countries, leading to more than 8000 infections and between 10 - 50\% mortality rate especially among elderly (WHO: https://www.who.int/csr/sars/ country/table2004_04_21/en/). MERS-CoV emerged in Saudi Arabia in 2012 from bats and camels as intermediary hosts spreading to another 27 countries and leading to 2494 infections with mortality rate of $20 \%$ to $40 \%$. later on, in 2014 it caused outbreaks of nosocomial infection in several hospitals in South Korea likely related to a medical doctor returning from the Middle East [1].

In December 2019 a new coronavirus pandemic infection started as clusters of adult cases of pneumonia of unknown aetiology, in Wuhan city, Hubei province, China. Few weeks later it strikes the whole world swiftly, looks like a World War III against an invisible enemy. That invisible enemy then identified as a Novel coronavirus and called sever acute respiratory syndrome coronavirus-2 (SARSCoV-2). It causes clinical infection called coronavirus infectious disease 2019 (COVID-19). Person to person transmission was identified as the main route for transmission with fast spread and strong nosocomial dissemination (N Engl J Med. 2020;382:1199-1207).

Coronaviruses have a tendency for rapid natural recombination and high mutation rates especially in the gene encoding the spikes protein of the viruses and in particular the Receptor Binding Domain (RBD). These recombination and genetic mutations al- 
low them to adapt to new hosts and ecological domiciles leading to novel type of coronavirus which spread from animal to humans (Lancet. 2020;395:689-697). However, other mutations in the gene are needed for the virus to replicate in the new host, hence the intermediate hosts. When the virus jumps from the animal host to the human via the intermediate hosts it will lose its infectivity in the previous animal source [2]. Until now we do not know exactly how the SARS-CoV-2 virus emerged, but probably as a result of rapid natural recombination and mutation similar to the acute respiratory syndrome coronavirus (SARS-CoV) 2002 and the Middle East respiratory syndrome (MERS-CoV) 2012 following animal to man transmission. The symptoms of SARS-CoV-2 infection manifest mainly as respiratory yet variety of atypical symptoms still evolving. The unique about this article, it is a comprehensive review of the published articles and communications about this pandemic. Unlike other short one-subject articles it included reviews and comments about several published researches particularly about immuno-pathophysiology, treatment options, prevention, vaccination trials, atypical cases reported and epidemiological issues with references to all of that.

\section{What is the SARS-CoV-2 virus?}

This is a large single stranded RNA virus with a virion size of 50 - 200 nanometer in diameter. Like other CoVs, it has 4 structural proteins namely: spike (S), envelope (E), membrane (M) and nucleocapsid $(\mathrm{N})$ proteins (Figure 3 ). The N protein holds the RNA genome while the other 3 proteins form the outside skeleton.

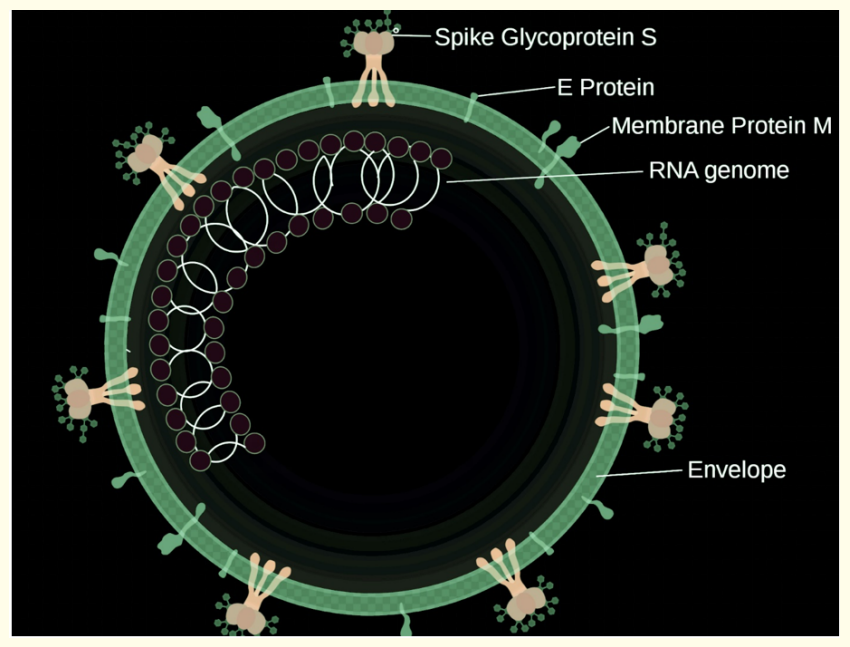

Figure 3: SARS-CoV-2 structures included the 4 main proteins.
Until now we do not know precisely from where the SARS-CoV-2 jumped to human. There are no studies to confirm $100 \%$ that it emerged as a result of a rapid natural recombination or mutation from bats. Similar doubts raised before about the acute respiratory syndrome coronavirus (SARS-CoV) 2002 and the Middle East respiratory syndrome (MERS-CoV) 2012 following like believe of animal to man transmission.

In a study about the phylogenetic network of the SARSCoV-2 from across the world, done in Cambridge University (PNAS. 2020;117(17):9241-9243; https://doi.org/10.1073/ pnas.2004999117), it has been found that there are at least 3 central variant of the virus named $A, B$, and C. Type $A$ is the ancestral form in China while type B is the common one in East Asia. Both A and $C$ found in significant proportions in Europe and America. Genetic mutation seems to be needed to allow the virus to overcome resistance outside its demographic zone such as type $B$ is adapted to East Asia while facing resistance outside it, so as it has to mutate to overcome this resistance. Type $C$, therefore, differ from the parents type B by the nonsynonymous mutation G26144T which changes a glycine to valine. Type $\mathrm{C}$ is the major European type and is absent in the mainland China. The virus is capable to mutate itself several times and in a parallel way (same mutation happen in many patients) and this may result in sub-clusters formation.

It has been reported that the virus emerged first as a cause for unexplained pneumonia cases in Wuhan city and that some of these cases exposed to the Huanan seafood market that sell live wild animal species. Transmission to other parts of China and worldwide occur quickly which overhauled and exhausting the health systems of most countries that were not prepared for such pandemic. On the $3^{\text {rd }}$ of January 2020 a novel coronavirus was identified from a patient bronchoalveolar lavage fluid in Wuhan which was confirmed by the Center for Disease Control and Prevention of China (CDC China) as the cause of these cases (China CDC Weekly. 2020;2:61-62). On 7 January 2020 the World Health Organization (WHO) named the virus 2019 novel coronavirus (2019-nCov) and 4 days later named the resultant clinical disease as COVID-19. With virus spreading rapidly in and outside China the WHO declared a Public Health Emergency of International Concern (PHEIC). This is the 6 time that the WHO declared PHEIC since the SARS 2003, Polio 2014, Ebola in West Africa 2014, Zika 2016, and Ebola in Congo 2019. Declaring PHEIC is an urgent call at the highest level, for the international community and governments to launch global coordinated efforts to stop the outbreak which requires strong and 
prompt public health response, high level of political commitments, and sufficient funding. As of early-June 2020 the total number of confirmed cases exceeded 6 million and will exceeds 7 million with a death rate of at least $6 \%$. In fact the actual non-reported cases are higher than the declared one (Brit Med J. 2020;368:m351). The epidemiological and clinical pattern of COVID-19 is yet to be understood especially in regards to its characteristics and transmission in pediatric and neonatal cases and effects on pregnancy. PostCOVID magnitudes of the diseases on health, educations, economy, psychology and other areas of life needs more studies and follow up. Moreover, this pandemic is a lesson to mankind to learn and prepare for worse than this, particularly if it is happening naturally, it will happen again.

In fact, we should learn a lot from the genome of the SARSCoV-2 for future researches, vaccines and treatment. It has been reported that the genome is closely related to the genome of SARSrelated CoV in Chinese horseshoe bats (bat-SL-CoVZC45) (Rhinolophus affinis) by $87 \%$ to $89 \%$ (Lancet. 2020;395:514-523). Pangolin identified as a possible intermediate host according to a study from Guangzhou, China (Figure 2). Pangolin is a scaly animal feeds mainly on ants or termites. It is endangered animal used both in Chinese Medicine and food. It is one of the most heavily trafficked animals around the world despite it is illegally traded or sold. The similarity of the CoV genomes from the Pangolins and from humans infected with COVID-19 reaching up to 99\%. It has been concluded from this that COVID-19 virus might have been originated from recombination of the virus that jumped from the horseshoe bat to the Pangolins then human [2]. More studies are needed to confirm this viral spillover and why the virus harbored in bats and intermediate hosts without infecting them? In fact, bats were in hibernating season when 2019-nCoV was first reported (winter time) and they were not reported to be sold in Wuhan animal market. Samples collected in January 2020 from the Wuhan market and return positive for 2019-nCoV by Real-Time Polymerase Chain Reaction (RT-PCR) were from 22 stalls, and one garbage truck all of them were in the west part of that market where wild-life trading occur [2]. Malayan Pangolins identified to act as a suspected intermediary host later in February 2020. Another 4800 samples from different animals including dogs, pigs, poultry, cats and others were studied and all came negative for 2019-nCoV, however, Turtles was a possible intermediate host too (BMJ. 2012;345:e4260).

There are no reports of transmission of COVID from domestic animals to human, nevertheless, there is one report from Nether- land about possible transmission of COVID-19 from Mink to man, cats and mink to mink [3]. Few cases of COVID-19 infection were reported in cats, dogs, tiger, ferrets and few cats in Wuhan found to have antibodies against SARS-CoV-2, while SARS-CoV-2 replicate poorly in dogs, pigs, chickens and ducks (Science. 2020:eabb7015; DOI: $10.1126 /$ science.abb7015).

Interestingly, it has been found that animals such as dogs, pigs, cats, and ferrets, had Angiotensin Converting Enzyme 2 receptors (ACE2) that favorable to SARS-CoV-2 binding a similar case in SARS-CoV-2003. The same receptors existed in human and used for attachment and cellular entry of both SARS-CoV-2 and SARSCoV-2003. The ACE2 receptor is an enzyme attached to the cell membranes of the outer surface tissues of lungs, arteries, heart, kidney and intestines. It lowers blood pressure by catalyzing the cleavage of the angiotensin II peptide (a vasoconstrictor) into angiotensin (a vasodilator). Theoretically, decreasing the ACE2 might help to fight the infection by reducing the viral attachment to the host cells. On the other hand, the ACE2 receptors provide a protective role for the lung via its vasodilatation effect. A systematic review and meta-analysis found that, the use of the ACE2 inhibitors was associated with a significant (34\%) reduction in risk of pneumonia and pneumonia related mortality compared to controls. The risk of pneumonia was also reduced in patients treated with ACE2 inhibitors who were at higher risk of pneumonia, in particular those with stroke and heart failure (BMJ. 345:e4260. doi:10.1136/ bmj.e4260. PMC 3394697. PMID 22786934). The S protein (Spike protein) is the main site that can bind to the host receptors (ACE2). Two factors are important in the susceptibility of individual to the infection, the number of ACE2 and the affinity of the S protein to the host ACE2 receptors. This affinity may depend on other factors and likely to be weaker in children. It has been found that the cellular serine called protease transmembrane protease serine2 (TMPRSS2) contribute to viral S-protein priming, which then helping the virus to gain easer entry into the host cells, hence the serine proteases TMPRSS2 inhibitors which are clinically approved for use might constitute a treatment option (Antimicrobial Agents and Chemotherapy; 2016.60(11):6532-6539; DOI: 10.1128/AAC.0104316). SARS-CoV-2 like all recent epidemics such as H1N1, SARS and MERS that the virus will reach a peak infectivity before attenuated by natural and effective factors which not only dropping its infectivity but coercing the virus to mitigate and the host immune system to work better. This is an intricate process which may be seasonally enhanced. 


\section{Basic reproduction rate ( $\mathrm{R} 0)$}

Basic reproduction $\mathrm{R}_{0}$ ( $\mathrm{R}$ zero) is an epidemiological factor used to determine if an emerging infection can spread in a population and proportion of population should be immunized to eradicate that infection. It is the number of cases of an infection generated by one index case and it is not an estimate of how fast is the infection. It depends on several factors such as geographical area, nosocomial spread-ability, environmental conditions, living circumstances and the behavior of the affected population. Similar factors affect the behavior of the curve of the epidemic, hence the curve shape varies according to many factors related to that particular area. When $\mathrm{R}_{0}$ is less than 1 it means the disease cannot spread to an epidemic proportion and when $\mathrm{R}_{0}$ is more than 1 it means the disease can spread as epidemic. The more the value above 1 the more likely for the epidemic to spread and the harder the measures to control it. On the other hand, the earlier measures taken to stop or contain the epidemic is the better to control the spread, this is where the transparency and early and right warning are needed.

The early $\mathrm{R}_{0}$ for SARS-CoV (2003) was 22 which went down to 0.3 - 2.9 when effective measures implemented while for MERSCoV (2012) $R_{0}$ was 30 then reduced to 0.5 - 3.5 with effective and early measures. This indicates that the super-spread-ability of both previous HCoVs epidemics were contained and reduced by overall effective measures to reach to less than $1(0.7-0.8)$ for both. It is therefore both previous epidemics of HCoVs started with high $\mathrm{R}_{0}$ and contained into a low potential risk for long-term sustained population transmission. SARS-CoV infections had not been reported after July 2003 but theoretically still able to re-emerge from bats to human again. On the other hand, MERS-CoV transmission to humans has continued, from dromedary camels as a reservoir and their close contact with humans but not as sporadic. The $\mathrm{R}_{0}$ for the new SARS-CoV-2 estimated at the start of the epidemic at 2.24 to 3.58 (Int J Infect Dis. 2020;92:214-217. doi:10.1016/j. ijid.2020.01.050.) which indicates the potential of this virus to cause epidemic outbreaks (Figure 4). However, following strict measures including lockdown and social distancing the estimated $\mathrm{R}_{0}$ reduced to average of $0.62(0.37-0.89)$ [4]. This means that COVID-19 is now showing positive signs of containment with measures resulted in halting the epidemic such as in China, Germany, South Korea, Spain, Italy, Switzerland, Austria, New Zealand, Australia, Canada, many Asian countries and the rest of the world on the right direction now to control it. The total number of cases in poor countries is much less than the advanced countries and the recovery is quicker and better possibly related to cross protection from the other mild common HCoVs in these countries.

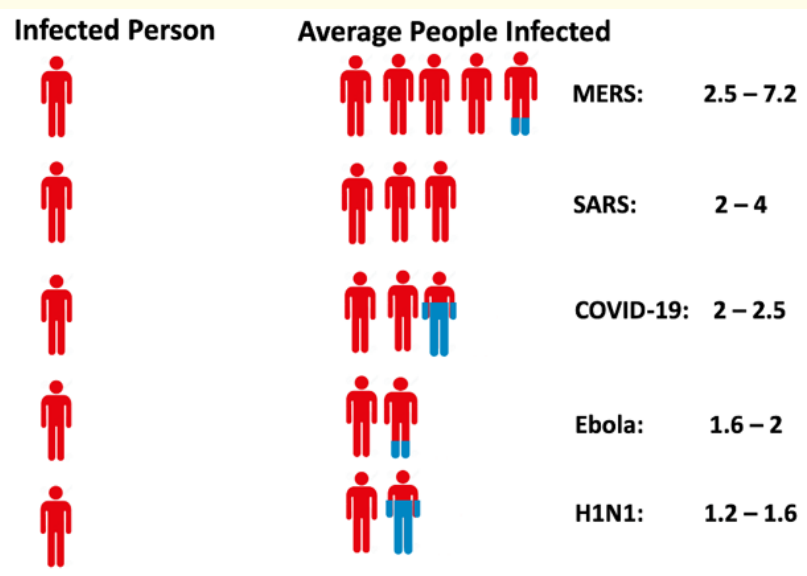

Figure 4: Reproduction of new cases (R0) from every index case.

The SARS-CoV- 2 mortality rate is up to $6 \%$ which is lower than SARS-CoV and MERS-CoV (6\% - 17\% and 20\% - 40\%, respectively) (China CDC Weekly 2020;2:61-62).

Pathogenesis and immunological response to $\mathrm{HCoV}$

There is currently lack of pathological and immunological data on SARS-CoV-2 infection, however, the pathological features are greatly resembled those seen in similar HCoVs such as SARS and MERS infections. Previous studies of similar HCoVs showed a multifactorial immune response which itself may trigger diffuse alveolar injury and hyaline membrane disease, clinically called Adult Respiratory Distress Syndrome (ARDS). In severe cases it may lead to serous, fibrinous and hemorrhagic inflammation in the pulmonary alveoli with capillary engorgement, and micro-thrombosis in some of these capillaries. It causes pulmonary hyaline membrane formation, desquamations of pneumonocytes, pulmonary edema and interstitial mononuclear infiltrate that are characteristic of ARDS. Before the development of the hyaline membrane and ARDS disease, lungs may show proteinaceous exudate, focal reactive hyperplasia of pneumocytes with patchy inflammatory cellular infiltration, and multinucleated giant cells U Thoracic Oncol. 2020; https://doi. org/10.1016/j.jtho.2020.02.010). Hence the timely and appropriate use of corticosteroids with ventilation may prevent or reduce the severity of ARDS. 
A leucocyte mediated cytokine lung injury has been suggested [5], hence in severe stages, patients with COVID-19 may benefit from treatment with IL-1, IL6, TNF-alfa and interferon- $\gamma$ blocking agents such as tocilizumab, sarilumab, infliximab and adalimomab and to prevent development of COVID associated pneumonia [6].

In China, Mesenchymal Stromal Stem Cells have been used to block the inflammation during ARDS stage [7]. Stem cells may also promote repair of the damaged lung tissue. Growth promoting factors such as Thiamine (Vitamin B1) play similar protective role for lung tissue which may be given at the start of the cough, (Experimental Lung Research. 1994;20:263-281. https://doi. org/10.3109/01902149409064387). Autopsies from COVID-19 patients showed jelly like liquid inside the lungs which is most likely occurred from the inflammatory cytokines storm (The Lancet Respiratory Medicine. 2020. https://doi.org/10.1016/S22132600(20)30076-X.). Proinflammatory Cytokines are strong inducer of Hyaluronan-Synthase-2 (HA-S-2) hence the production of defected Hyaluronic acid (HA) which then promote tissue damage and respiratory failure. The use of anti-HA such as hyaluronidase may benefit the severe patients who required ventilation.

Interestingly most inflammatory cells found in the viral antigen containing alveoli are Angiotensin Converting Enzyme 2 (ACE2) receptors cells that the virus use to gain entry inside these cells ( $\mathrm{Vi}$ rology. 2009;395(2): 210-222. doi:10.1016/j.virol.2009.09.023). Clinically SARS-CoV-2 infection divided into 3 stages, asymptomatic stage (incubation period), mild to moderate stage and severe stage. A specific adaptive immune response required to prevent the virus from spreading into severe stage. Strategies to boost that immune response during the first two stages can be achieved by passive immunity with monoclonal or polyclonal antibodies (anti-serum) which can be extracted from recovered patients, and or antiviral drugs such as pegylated IFN $\alpha$ (which is immunomodulator to suppress viral replication as in hepatitis (C and B) or other antivirals however there is no specific antiviral yet used against SARS-CoV-2. Combination of antivirals that works in different mechanism may be better than antiviral monotherapy.

The immune response to SARS-CoV-2 may vary according to the background genetics such as Human Lymphocytes Antigens (HLA) which plays essential role in fighting viral infections in general [8]. If the immune system compromised, the SARS-CoV-2 virus propagate and may lead to severe damage to the tissues that contains high concentrations of Angiotensin Converting Enzyme 2 receptors
(ACE2) (lung, intestine, kidney, mouth and tongue). These damaged tissues themselves will then initiate innate inflammation in the lung via the production of proinflammatory macrophages and granulocytes. Inflammatory pulmonary damage is the main cause for life-threating respiratory disorder when severe stage of COVID-19 reached, therefore, it may help to suppress the inflammation in addition to other supportive measures [5]. The hypothesis of the ACE2 receptors and viral entry needs more studies, however, it has been shown that the ACE2 become less abundant and may be defected in old age which may also abate their protective role for pulmonary tissues. It seems therefore that in HCoVs infections such as SARS-2003 and SARS-CoV-2 that while the virus used the ACE2 as a keyhole entry inside the cells on the same time it leads to its exhaustion in the old patients which will result in losing its protective role that already abated due to aging. In young patients the reverse is true as the ACE2 is high in numbers with intact protective role (Nat Commun; 2014;5:3594, https://doi.org/10.1038/ ncomms4594). The ACE2 in children are immature hence less likely to act as an easy key hole for virus entry yet it maintains its pulmonary protective role leading to less severe infection, but this is yet to be proved by more detailed studies.

Other studies showed that the counts of peripheral CD4 and CD8 $\mathrm{T}$ cells in patients with COVID-19 were substantially reduced, while their status was hyperactivated. The highly pro-inflammatory Chemokine Receptor 6 produced by T helper 17 (CCR6+ Th17) in CD4 T cells were increased and the CD8 T cells were found to harbor high concentrations of cytotoxic granules (perforin and granulysin). This hyperactivation and cytotoxicity may account in part to the immune injury and might be an early sign for the virus activity. It seems to be just before the symptomatic recovery in patients with mild to moderate COVID-19, the body's immune system triggered [5]. This has been shown as an increase in antibody-secreting cells (ASCs), follicular helper T cells (TFH cells), activated CD4+ T cells, CD8+ T cells, immunoglobulin M and G (IgM and IgG) antibodies that bound the coronavirus SARS-CoV-2. This activation started at day 7 of the illness, peaked in day 8 and coincided with reduction in the viral load (viral clearance started). On the other hand, TFH cells which play an important role in antibody production emerged at day 8 of the COVID-19 illness. We know that both ASCs and TFH cells are key in post influenza-A vaccinations. These immunological changes persisted for at least 7 days following full resolution of symptoms. The SARS-CoV-2 IgM and IgG antibodies continued to increase from day 7 until day 20. On the other hand, the mono- 
cytes shift from blood to the site of infection and play important role in the resolution of the symptoms and the viral clearance. One therefore, can conclude that when the immune system (cellular and antibodies) triggered by day 7 of the illness, the clinical recovery started and this is similar to what happened in influenza A infection hence when vaccine produced it should trigger immune response in short time. The use of serum from recovered patients can therefore provide cellular and antibody protective immunity for patients whose immune system remained silent and clinically not improved after day 7. This can be checked by IgM and cellular monitoring from day 7. It seems that the young immune system in children and immature ACE2 receptors play a positive role to maintain mild symptoms. It is interestingly that in SARS-2003 the number of children was only $10 \%$ while in CoV-SARS-2 studies from China showed only $0.9 \%$ are children less than 9 years old and $1.2 \%$ are children and adolescent between 10 - 19 years old [9]. Children may also suffer from severe COVID-19 symptoms requiring intensive care admission and can stay in hospital for long time and few cases were died including premature baby for a COVID-19 positive mother [10].

Studies therefore showed that both antibodies and cells immune systems particularly $\mathrm{T}$ cell response (CD4+ helper T cell and CD8+ T cells) are needed to fight the coronavirus COVID-19. The earlier the activation of this immune response the better the outcome and the milder the symptoms hence the serious infection in immunocompromised and older individuals. If symptoms not improve after 7 - 8 days, other causes should be sought including secondary infections or complications such as ARDS in addition to the lack of activation of immune system. In children and young adults, the immune system is younger, more active, balanced and less defective. The balance between the inflammatory response when needed and the exit of this response when not needed seems to be more complicated than just T-helper 1 (Th-1) and T-helper 2 (Th-2) cells and needed more evaluation and studies. It is not known why some patients become positive again after discharge, however, this may be related to the immune system (International Journal of Infectious Diseases. 2020, doi:https://doi.org/10.1016/j.ijid.2020.03.007) and (Research Square. 2020; DOI:10.21203/rs.3.rs-23197/v1). The virus-eliminating immune response to SARS-CoV-2 may be difficult to induce in some patients, hence the infection may relapse again and become SARS-CoV-2 positive after discharge. The use of antiserum in these patients after checking the immune responses before discharge may prevent relapses. Vaccines may not work in these individuals and they should be monitored for the virus together with T/B cell responses and Immunoglobulins [11].

Interestingly children less than 5 years showed more severe infection with seasonal and pandemic influenza A than with COVID-19 [12]. The lesser number of COVID-19 in children may be due to slight or no symptoms, due to their immune system responses. Cross immunity resulted from recurrent infections with the other common HCoVs is more in children than adults who cannot maintain immunity to HCoVs in contrast to many other respiratory infections. More studies needed that might help in finding a vaccine or proper immunological activating agent that help treat or at least reduce disease severity. On the same time the impact of COVID-19 on pregnancy and on the fetuses and the neurodevelopmental outcome for babies is yet to be elucidated. While everyone is busy to stop the spread of the disease now and to prevent its recurrence, in future the heterogenicity of immune response may help to provide a vaccine or treatment especially that the CoVs viruses will continue their natural genetic mutation that may result in more fatal and more rapidly spreading virus in future. This happened in 2003 than 2012 then 2020, with gaps of 8 to 9 years. This may predict another outbreak between 2027 to 2030 or even earlier. In fact, an international strict law preventing the illegal marketing of the wild animals is urgently needed and an international law determined the responsibilities of all states and governments to raise the alarm as early as in first cases if the danger of an outbreak is expected. Law makers should act on international level and may need a new body mainly dealing with infectious diseases alarm system with or outside the World Health Organization (WHO) accountability.

\section{Clinical features of HCoVs in children}

\section{Clinical features of the common HCoVs}

The 4 common RNA coronaviruses (229E, NL63, OC43 and HKU1) are globally endemic and usually transmitted via airborne droplets mainly to the nasal mucosa, then enter to the local ciliated epithelium, causing localized cell damage and inflammation. After 5 - 10 days humeral (local IgA and general IgM) and cellular immunity developed followed by resolution of the cold like symptoms. Immunity can be cross-protecting between the 4 viruses and maybe also included the other HCoVs (SARS-2003, MERS and SARSCoV-2). Clinically the common HCoVs cannot be differentiated from the other respiratory viruses such as the influenza viruses, the Respiratory Syncytial Virus (RSV) and the enteroviruses by causing cold like symptoms such as fever, sore throat, rhinitis, pharyngitis, 
otitis media, laryngitis, headache, body-ache, bronchopneumonia, bronchiolitis, asthma exacerbation, croup, conjunctivitis, febrile seizures, gastrointestinal symptoms, and rarely acute disseminated encephalomyelitis (PLoS One. 2018;13(1):e0191789. Published 2018 Jan 29. doi:10.1371/journal.pone.0191789) and (Pediatrics. 2004;113(1pt1):e73-e76). However, myalgia, sore throat, fatigue, and headache are more common in HCoVs infected patients while fever, cough and dyspnoea are more predominant symptoms in patients infected with other respiratory viruses like RSV, influenza, enterovirus and rhinovirus (Viruses. 2018;10(10):515. Published 2018 Sep 21. doi:10.3390/v10100515). The viral load in HCoVs common infections is high in the first 48 hours then gradually decreasing until 14 days and virus particles can be isolated from asymptomatic individuals too [13]. Occasionally they may cause sever disease in frail subjects but do not cause major epidemics.

\section{Clinical features of SARS-CoV (2003)}

In SARS-CoV (2003), children had no fatality and their symptoms are less severe than adults. These symptoms in a rank of most common are fever (90 - 100\%), cough (up to 80\%), rhinitis (up to $60 \%$ ), myalgia (up to $40 \%$ ), headache (up to $40 \%$ ), and between 10 - 20\% may have vomiting, diarrhoea, abdominal pain, febrile seizure and breathlessness. Between 50 - 80\% had one family member affected and up to $30 \%$ had nosocomial infection [14]. Children usually recover quicker than adults however chest computed tomography (CT) changes such as air trapping and ground glass appearance may persist for many months [15]. There are no reported vertical transmission, however it may cause miscarriage, intrauterine growth retardation and preterm delivery if mother has SARS-CoV during pregnancy [16].

\section{Clinical features of MERS-CoV (2012)}

In MERS-CoV (2012) only up to $4 \%$ of cases are children [17]. Fever were reported in 57\%, gastroenteritis in $28 \%$ and cough with or without dyspnoea in $14 \%$. Mortality rate in children reported in $6 \%$. The main source of infection is community acquired (55\%) while $19 \%$ reported to be nosocomial and the rest unknown. Out of 8 MERS-CoV cases reported in pregnant women 3 infants died [18].

\section{Clinical features of SARS-CoV-2 (2019) (COVID-19)}

There is insufficient knowledge about the existing rapidly spreading global pandemic of SARS-CoV-2. Although it is of a major international concern now but one may speculate and based on previous behavior of the HCoVs epidemics and H1N1 that it may naturally soon revolve into a low-level endemic infection. This may occur as a result of development of adequate immunity, our immune system become conversant with this virus (not as new anymore) and herd immunity. The virus tried to mutate to be stronger but its mutation gets it weaker resulting in a weakened virus that offer development of a natural global herd immunity. In general SARS-CoV-2 infection can roughly be divided into 3 stages. Stage 1, an asymptomatic period (incubation) with or without detectable virus, stage 2 , mild to moderate symptoms with virus detection and stage 3, severe symptoms with Adult Respiratory Distress Syndrome (ARDS) which occur in 15\% of cases particularly the older age groups, immunocompromised and comorbid.

In a case series of 2143 pediatric patients with COVID-19 in China, $34.1 \%$ were confirmed cases and $65.9 \%$ were suspected. Age 2 - 13 years old with $56.6 \%$ were boys. Asymptomatic to moderate cases were the majority (90\%) of children cases and it is less severe than adults though younger children particularly infants and children with other comorbidities like heart or pulmonary diseases were more vulnerable to sever infection. Pregnancy also is a risk factor for sever infection but vertical transmission not yet reported [19] (Centers for Disease Control and Prevention website. https://www.cdc.gov/coronavirus/2019-ncov/hcp/guidance-risk-assesment-hcp.html. Published March 7, 2020. Accessed March 27, 2020). Children infected with SARS-CoV-2 are more likely than adult to have coinfections. The median time from illness onset to diagnoses was 2 days (range: 0 to 42 days). Disease rapidly spread from Hubei Province to surrounding areas. More children were infected in Hubei province than other provinces. There is one death reported which make death rate in children around 0.5 per $1000(0.05 \%)$ that is much less than the adult death rate which is around $4.2 \%$ globally. In another case series studies from Wuhan Children Hospital between January and February 2020 of 20 confirmed children with COVID-19 by pharyngeal swabs that is positive for RT-PCR, it has been found that children cases started to emerge when the number of adults increasing [20]. Most children infections happened after household contact with adults and presented with upper respiratory tract symptoms that are similar to the other upper respiratory viral infections. Around $40 \%$ of children may have superimposed infection by other pathogens which can be detected by other PCR swabs and should not role out COVID-19 when done first. Moreover, the upper respiratory swab for COVID-19 PCR test can be false negative due to low detection rate at an early stage. Many of these cases that reported negative from upper respiratory swabs had positive test from the lower respira- 
tory aspirate. In the same study $65 \%$ of cases were boys and $35 \%$ girls. This possibly related to the effect of the $\mathrm{X}$ chromosome on the innate immune system dimorphism [21]. Patients age was ranging from 1 day to 14 years; $15 \%$ neonates ( $<1$ months), $55 \%$ aged 1 months to 3 years and $30 \%$ above 3 years. Contact history reported in $65 \%$ and the rest were uncertain. Fever and cough were the commonest symptoms however, diarrhea, nausea, vomiting, rhinorrhea, fatigue, sore throat, taste changes, anosmia, dysgeusia, hypogeusia, ageusia, and tachypnea were also reported. Other rare findings were sinus tachycardia, epilepsy as a sequela of previous viral encephalitis, history of atrial septal defect surgery, atrial arrhythmia, first-degree atrioventricular block, atrial and ventricular premature beat, incomplete right bundle-branch block, chest angina like pain and variety of cardiac presentations [22]. The average stay in hospital was 12.9 days (8 - 20 days). Eighteen children were discharged home after negative swabs and only two neonates remained in to get negative swab and no death rate.

The most common clinical features caused by COVID-19 are respiratory and gastrointestinal symptoms ranging from common cold to sever diseases such as pneumonia, bronchiolitis, sever acute respiratory distress syndrome, multi-organ failure, encephalitis, hepatitis, coagulopathy disorders and death. HCoVs have also been associated with exacerbations of chronic obstructive pulmonary disease, cystic fibrosis and asthma. Sudden death may occur possibly related to sever myocarditis, encephalitis in addition to respiratory failure. Mortality rate increased by old age, obesity and presence of comorbidities may be due to weak immune system (Lancet. 395(10223);507-513). More men infected than females for an unknown cause but may be related to the $\mathrm{X}$ chromosome and the innate immune system and female hormones that reduce the viral infections and the way the immune system deal with them in a way of sexual dimorphism [21].

Five categories of patients identified based on the severity of their symptoms:

1. Replicative asymptomatic stage: No symptoms or fever and normal chest X ray or CT scan but positive 2019-CoV RT-PCR test. Viral replication occurs over a period of several days. An innate immune response occurs, but this response may fail to contain the virus. More studies are needed about the structural proteins of the virus which might act to inhibit the immune system allowing more time to replicate. This is another area to produce antiviral that convert the COVID-19 into a mild in- fection. Following the initial asymptomatic stage around day 7 of illness, the immune system starts to kick off and viral load decrease over another 7 days. However, the immune response can be so severe (cytokine storm) leading to sudden deterioration and tissue damage hence the initial mild symptoms cannot predict this sudden deterioration.

2. Mild: Fever but not in all cases, fatigue, myalgia, cough, sore throat, conjunctivitis, rhinorrhea, and sneezing. Examination shows throat congestion, and clear chest. Some cases have only gastroenteritis symptoms.

3. Moderate: Frequent fever, cough (mostly dry followed by productive), pneumonia, wheezing, no hypoxemia, no dyspnea, and the CT may show lung lesions.

4. Sever: In addition to other symptoms there will be dyspnea, with central cyanosis and hypoxia of $\mathrm{SaO}_{2}$ less than 92\% early in the disease and progress rapidly over 7 days.

5. Critical: It has been noted in Wuhan that children can rapidly progress to acute respiratory distress syndrome (ARDS) and or respiratory failure and shock but less than adults. Encephalopathy, myocardial damage and heart failure, coagulopathy and acute renal injury have been reported in children. Multiple organ failure can be life threatening.

Different neurological features were reported and some of them may persist after recovery which are either due to direct neurotropic effect of the virus or immune related effects hence more studies needed [23] (Neuroscience. 2020;11(9):1200-1203; DOI: 10.1021/acschemneuro.0c00172). In a study [24] of 58 COVID-19 positive patients with median age of 63 years in France, neurological features reported in 14\%. These features were agitation, confusion, corticospinal signs (enhanced tendon reflexes, ankle clonus, bilateral extensor plantar reflexes), and dysexecutive syndrome (inattention, disorientation, poorly organized movements). Magnetic resonance imaging of brain (MRI) in some showed non-specific finding of focal hyperintensity and subacute ischemic stroke. Electroencephalography (EEG) showed nonspecific changes one of them was consistent with encephalopathy. Cerebrospinal fluid (CSF) was normal and negative for SARS-CoV-2 in all 8 patients. These features are not necessarily viral related but more likely management related. Theoretically this could be due to direct viral damage to the nervous system, the immune response of the host, the systemic effects and the management itself. SARS-CoV-2 might also presented as a late neonatal sepsis that required PICU admission and ventilation [25]. 
Children in schools and nurseries are more prone to have the upper respiratory tract infections due to the common mild alpha coronaviruses and the resultant immunity might provide them with cross-protective antibodies and cellular immunity against the COVID-19. Children seem to have quality of ACE2 receptors that strong enough or not yet suitable for the virus to gain entry into the cells. This is something need more studies.

Clinicians should be aware of atypical presentations of SARSCoV-2 in children or adults such as axial hypotonia with fever or respiratory symptoms, toxic shock like syndrome or Kawasaki disease (KD) like presentation called Pediatric Inflammatory Multisystem Syndrome (PIMS) (two death reported one in the UK and one in France), abdominal and testicular pain with backache, neonatal infection or RDS, and oro-nasal chemosensory dysfunction (Lancet. 2020; Published: April 27, 2020; DOI: https://doi. org/10.1016/S01406736(20)30980-6); (https://picsociety.uk/ wp-content/uploads/2020/04/PICS-statement-re-novel-KD-C19presentation-v2-27042020.pdf); (Am J Emerg Med. 2020;S07356757(20)30194-7. doi:10.1016/j.ajem.2020.03.052); UAMA Pediatr. Published online March 26, 2020. doi:10.1001/jamapediatrics.2020.0878); (International Forum of Allergy and Rhinology, 2020; DOI: 10.1002/alr.22579). The association of KD and the common HCoV was questioned before and refuted [26]. However, there is biochemical evidence of vasculitis changes in some patients with SARS-CoV-2. This vasculitis most likely related to the cytokine and other inflammatory reaction which then may cause atypical cases of KD or COVID-19 pediatric multisystem inflammatory syndrome (PIMS) in susceptible children [27]. The role of vitamin D in immune mimicry and the resultant vasculitis and respiratory reactions were questioned before [28] none of the patients with SARSCoV-2 and KD have their vitamin D concentrations measured. More emphasis on this interesting point is needed particularly in cases with slow recovery or unexplained sever presentation.

Interesting to know, variable cutaneous lesions were reported including different kind of skin eruptions likely to appear with other symptoms (vesicular, maculopapular, livedo, necrosis, dengue like rash), toes pseudo-chilblains (late in the evolution of COVID), urticarial lesions, petechial rash, and some of the rashes may be drug hypersensitivity [29] (Br J Dermatol. 2020; doi:10.1111/ bjd.19163); (Allergy. 2020 doi: 10.1111/all.14238); Uournal of the American Academy of Dermatology (2020), doi:https://doi. org/10.1016/j.jaad.2020.03.036); (Zhonghua Xие Ye Xие Za Zhi.
2020;41(0):E006. doi: 10.3760/cma.j.issn.0253-2727.2020.0006). In one study it has been found that children infected with SARSCoV-2 requiring hospital admission showing bimodal distribution. Hospital admissions were more in the younger age group less than 1 year old and those over 15 years old and more likely to be when there is comorbid illnesses [30]. COVID-19 is a significant traumatic event that can affect the mental health specially of the health workers like nurses and doctors and other people as a result of the lockdown, social distancing and loss of the income source for many families and individuals. Mental health issues such as depression, anxiety, phobias, psychosis, suicides, social breakdown and psychosomatic effects needed more studies [31].

\section{Transmission of 2019-nCoV}

Transmission of any contagious infection depends on many factors. The top 6 factors are the nature of the infectious agent, the reservoir, the route of exit, the route of entry, the mode of transmission and the susceptible hosts. Until now we know little about these factors in relation to SARS-CoV-2. From some early studies the SARS-CoV-2 looks like a hit and run virus that can remains after a strike in-hiding on surfaces, Personal Protective Equipment (PPE), Fomites, air, hands, body fluids, stool, utensils, and others between few minutes to many hours on a standby to attack a new host again before it expires or killed by disinfectants. It can stay viable in air for 3 hours, on plastic for 72 hours, on stainless steel for 48 hours, on copper for 4 hours and on cardboard for less than 24 hours [32]. Plastic and stainless-steel surfaces therefore act as a good hiding places for the virus to remain doable for many hours. On dry surfaces it might remain so for up to 9 days. Moreover, the virus was isolated from equipment and vents that possibly due to virus-laden droplets displaced by airflows (JAMA. Published online March 04, 2020. doi:10.1001/jama.2020.3227).

The strong nosocomial transmission of SARS-CoV-2 requires effective comprehensive sterilization program and PPE to prevent hospital transmission. One of the most important keys to interrupting viral transmission to and from the health workers is the proper removal of the contaminated PPE [33] (See figure 5). Health workers may carry the virus without being symptomatic. In a study [34] by screening asymptomatic healthcare staff carried out in Cambridge the UK, it has been shown that $3 \%$ of the healthcare staff who showed no symptoms or very mild symptoms are career for SARS-CoV-2. This is something have to be considered in eradication prevention. 


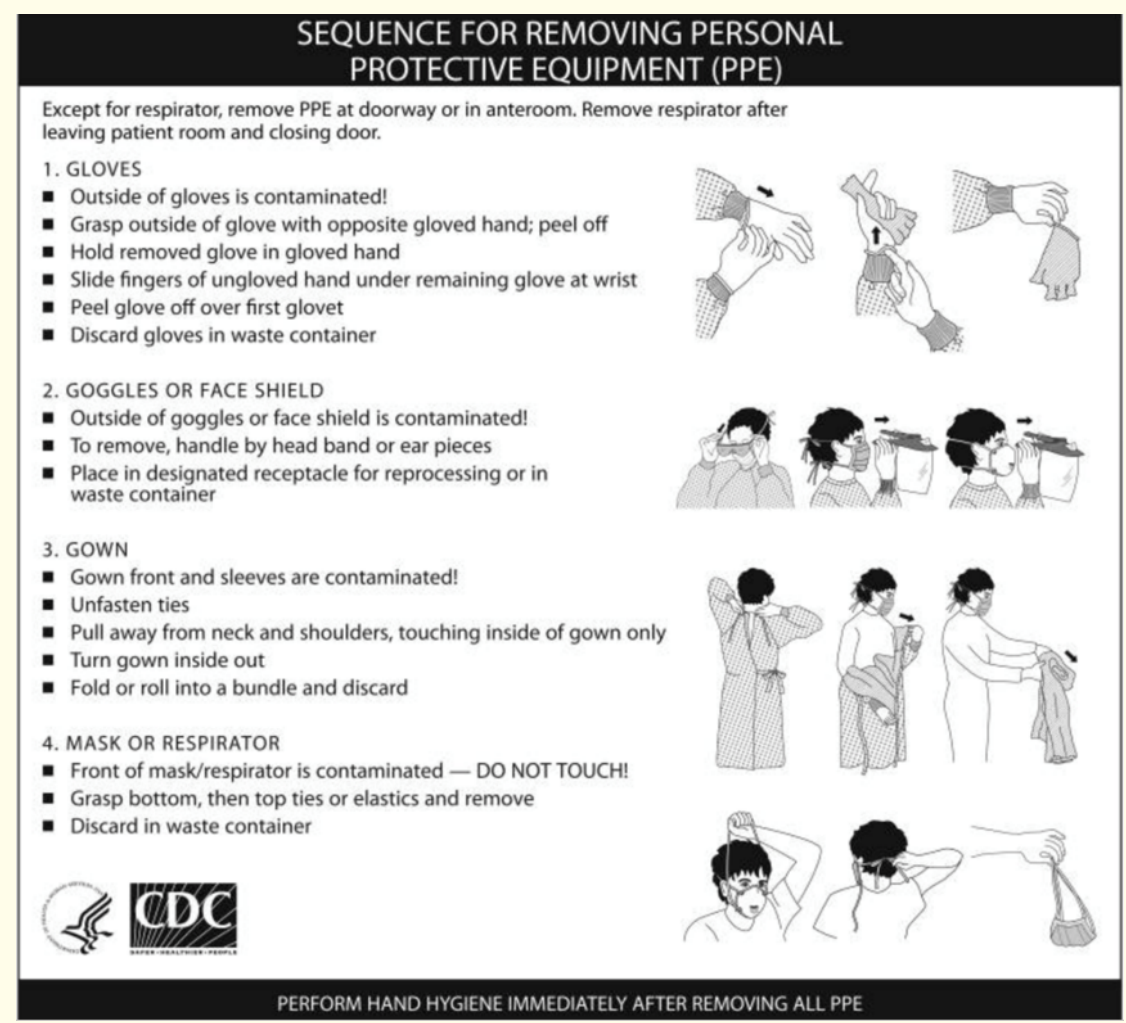

Figure 5: Proper way to remove PPE [33].

The effect of Ultra-Violet (UV) radiation was questioned whether effective or not? It is well known that the UV radiation can kill some viruses by damaging their genetic material. This process happens better in a wavelength of $260 \mathrm{~nm}$ which is outside the groundlevel sunlight, however, the primary photochemical processes that damage the viral DNA or RNA occur at all the solar UV wavelengths, varying only in the efficiency of the different wavelengths. Two important factors needed to do that, the viral sensitivity and the geographic location. UV light usually damage the viral genome and not other viral structures. The UV light will damage the thymine dimers; hence the DNA viruses are generally more sensitive to damage by UV than RNA viruses that not containing thymine [35]. SARS-CoV-2 is a single stranded big RNA virus that will likely be damaged by the solar UV light hence its survival during summer time maybe less likely. This is another aspect for more studies.

SARS-CoV-2 might have feco-oral transmission with the virus remained shedding for longer time even after the upper respiratory swabs turn negative. The virus isolated by RT-PCR from stool sample and rectal swabs in patients with mild to moderate COVID-19 symptoms [36]. Interestingly the rectal swab remained positive following the pharyngeal swab turn negative which may determine the quarantine period in patients with diarrhea. It is known that HCoVs can be excreted and possibly transmitted by urine [2]. Asymptomatic individuals can have prolonged nasal and throat viral shedding and so the virus will be transmitted in the absence of clinical symptoms [37]. Children can transmit the virus to others despite the mild symptoms. Aerosol transmission during medical procedures such as nebulization is a likely possibility [38] and that kind of transmission is a well-known for other viruses such as Measles where the virus can linger in the air for many hours. This leads us to the question whether we need to take airborne precautionary measures or not, a situation of such pandemic an airborne precaution should not be denied at all to contain the virus effectively. In addition to sterilization, ventilation, aeration and proper distancing of at least 2 meters should be observed. Careful use of aerosol medications and nebulization should always be contemplated. 
Laboratory and radiological findings and diagnosis

The only specific test to confirm the infection is isolation of the viral antigen by Real Time Polymerase Chain Reaction (RT-PCR) test. Sample in cases of upper respiratory tract infection is nasopharyngeal aspirate or oropharyngeal swabs (non-cotton flocked swab) and in lower respiratory infection is deep respiratory samples (sputum or deep tracheal aspirate or bronchoalveolar lavage in intubated patients).

There have been reports that the lower respiratory secretion yields more positive results due to the viral load, hence in highly suspected cases with negative upper secretion test, it is recommended to do lower secretion test (Lancet. 2020;395:514-523). RT-PCR may be positive on stool samples but not validated for routine use. Serological testing for antibodies (Ig M) is not routinely used and may cross react with the common $\mathrm{HCoV}$ infections.

Other blood tests finding are non-specific and similar to any viral infections. The white blood cell count is usually normal or low. Neutrophil, lymphocyte and platelets may be low too. The C-reactive protein and procalcitonin concentrations are often normal. In severe cases liver enzymes, lactate dehydrogenase, D-dimers and coagulation profiles may be elevated. In a series of cases admitted to Wuhan Children hospital of confirmed COVID-19 (Lancet; 2020; Published: April 27, 2020; DOI: https://doi.org/10.1016/ S01406736(20)30980-6), it has been found that white blood cell counts were normal in $70 \%$ of cases, low in $20 \%$ and increased in $10 \%$. Lymphocytes percentage decreased in $35 \%$ and increased in $15 \%$. Creatine kinase-MB increased in 75\%; C-reactive protein (CRP) increased in 45\%; and procalcitonin (PCT) increased in $80 \%$. Coinfection with other pathogens were more than adults and reported in $40 \%$ of children cases, including influenza viruses $\mathrm{A}$ and B, mycoplasma, respiratory syncytial virus, and cytomegalovirus. Four cases had abnormal electrocardiogram events but it is not clear if the same patients had increase in creatine kinase-MB which is increased in pericarditis and myocarditis.

The chest X -Ray in children commonly show bilateral peripheral patchy consolidations, peri-bronchial thickening and groundglass opacities. Chest CT scan may show nonspecific finding ranging from bilateral multiple nodular to speckled ground-glass opacities, infiltrating shadows in the middle and outer zone of the lung or under the pleura, but single nodules has been reported too (Zhonghua Er Ke Za Zhi. 2020;58:E007).
In a study in Wuhan Children Hospital (Lancet; 2020; Published: April 27, 2020; DOI: https://doi.org/10.1016/ S01406736(20)30980-6), the chest CT scan finding were divided into early, advanced and critical stages. In the early stage CT scan may show no pulmonary abnormalities in $50 \%$ of cases including neonates, 30\% showed unilateral pulmonary lesions, and 10\% showed bilateral pulmonary lesions. Interestingly all children in the early stage showed Subpleural lesions with localized inflammatory infiltration. Consolidation with surrounding halo sign observed in $50 \%$ of cases, ground-glass opacities in $60 \%$, fine mesh shadow in $20 \%$, small nodules in $15 \%$. There were no signs of pleural effusion or lymphadenopathy. Ground-glass opacities and consolidation coexist and may be accompanied by interlobular septal thickening, fibrosis lesions, or air bronchogram signs. In critical stage the chest CT scan showed that the consolidation lesions were diffuse and involving both lungs, presenting as a "white lung" change, accompanied by air bronchogram. The lesion density was heterogeneous, accompanied by ground-glass opacities and pleural thickening. During recovery stage and after treatment, a chest CT follow-up was obtained in six cases. Lesions were completely absorbed in two cases (10\%), consolidations turned into groundglass opacities and gradually decreased in three cases (15\%) and residual fiber strip remained in three cases (15\%).

Blood tests that important to be done in confirmed cases for monitoring and management are as in table 1.

Table 1: Initial blood tests on admission of confirmed cases.

1. Complete blood count and differential with blood group

2. Serum Electrolytes including calcium, magnesium and uric acid

3. Serum Glucose

4. Urea and Creatinine

5. Liver Function test and enzymes

6. C-Reactive Protein, leucocyte dehydrogenase (LDH) and Procalcitonin

7. Serum amylase and lipase

8. G6PD (chloroquine may be considered)

9. Blood gas

10. Coagulation profile and D-Dimer

11. Respiratory panel PCR and streptococcal antigen detection swab tests (superimposed infections)

12. Atypical PCR panel (Mycoplasma, chlamydia, legionella)

13. In immunocompromised patients might consider other investigations such as blood culture, sputum culture, tuberculosis, atypical infections

14. Chest X Ray and high resolution chest CT scan (in asymptomatic patient impact on management)

15. Baseline ECG (look for QT prolongation) (avoid QT prolongation drugs such as Fluoroquinolones, Macrolides, Azoles, Ivabradine, Anti-emetics, Anti-depressant, Antipsychotics and Antiarrhythmic. 


\section{Treatment}

There is no specific antiviral treatment or vaccine against SARS$\mathrm{CoV}-2$ yet. The mainstay treatment is supportive and treatment of comorbid conditions. Oxygen, fluid, calories intake and prevention of ARDS and organ failures are important. Secondary bacterial infections may need empirical antibiotics such as second-generation cephalosporin and or macrolides such as azithromycin.

During previous outbreaks of SARS-CoV 2003 and MERS-CoV 2012, many medications [39] were used however all of them were inconclusive or associated with unfavorable side effects. There was no specific anti- SARS-CoV antiviral. The following were used inconclusively:

1. Interferon alpha and beta

2. Ribavirin (associated with hemolytic anemia and liver dysfunction).

3. Interferon-alpha

4. Intravenous corticosteroids it may delayed viral clearance, and cause avascular necrosis, osteoporosis, and diabetes.

5. Lopinavir/Ritonavir (Kaletra)

6. Intravenous immunoglobulins

7. Monoclonal antibodies

8. Mycophenolate mofetil: may cause lung damage and severe outcome in MERS-CoV.

During the current SARS-Cov-2 pandemics there is no definitive evidence for all treatments used. One treatment recommended for children patients, is the use of nebulized interferon alpha- $2 b$ and oral lopinavir/ritonavir together with corticosteroids for complications such as ARDS, encephalitis, hemophagocytic syndrome or septic shock. Intravenous immunoglobulin may be used for severe cases yet there is no clear benefit from these drugs in children (World J Pediatr. 2020. Feb 5. doi: 10.1007/s12519-020-00345-5).

The viruses cause SARS-CoV (2003), MERS-CoV (2012) and SARS-CoV-2 use several glycoproteins in their spikes to bind to the host cell and one of them is glycoprotein $S$ which is responsible for virus cell binding. The use of monoclonal antibodies to block the glycoprotein $\mathrm{S}$ have been shown to inhibit SARS-CoV-2 fusion with the host cell reducing infectivity and mortality (Sci Transl Med. 2014;6:234ra59). Glycoprotein S was also blocked in animal studies by red algae called Griffithsia. The monoclonal antibodies may work on the cell receptors used by the virus for attachment and entry such as Angiotensin-converting enzyme 2 (ACE2), dipeptidyl peptidase 4, aminopeptidase $\mathrm{N}$, and $\mathrm{O}$-acetylated sialic acid however more studies are needed. The ACE2 serves as the entry point into cells for some coronaviruses including SARS and SARS-2. Some believe that decreasing the ACE2 will make them less available for the virus which might help to fight the infection. However, lung damage occur following $\mathrm{HCoV}$ might be related to degradation of ACE2 receptors and attenuation of their protective role for the lung via its vasodilatation effect. Furthermore, the use of ACE2 inhibitors may lead to compensatory increase in the number of ACE2 receptors like what happened in patients treated with ACE2 inhibitors for hypertension, cardiovascular diseases and kidney diseases Uournal of Travel Medicine, taaa041, https://doi.org/10.1093/jtm/ taaa041). Researches have also shown an increase in number of ACE2 receptors in the cardiopulmonary circulation after intravenous infusions of ACE inhibitors. One may conclude therefore that there are 3 possible explanation in relation to ACE2 and the severe respiratory symptoms in COVID-19, degradation of ACE2 by the virus leading to lack of its lung protective role, the rebound increase in ACE2 when the ACE2 inhibitors used making more sites available for the virus and the same effect resultant from the chronic use of ACE2 inhibitors in these patients. Hence in ventilated COVID patients care need to be taken when using ACE2 inhibitors that if properly used it may reduce respiratory morbidities and complications.

In a systematic review and meta-analysis study (BM). 2012;345:e4260) it has been found that the appropriate use of ACE inhibitors was associated with a significant 34\% reduction in risk of pneumonia compared with controls. The risk of pneumonia was also reduced in patients treated with ACE inhibitors who were at higher risk of pneumonia, in particular those with stroke and heart failure. The use of ACE inhibitors was also associated with a reduction in pneumonia related mortality, although the results were less robust than for overall risk of pneumonia in adults.

Enveloped viruses like SARS-Cov-2 may enter into the cells through the fusion of their envelope with the plasma membrane via endosomal and non-endosomal proteases entry. So as, other ways of treatment are to block these fusion entries. This entry happened when the Spike (S) protein of the virus bind to a surface metalloprotease called human aminopeptidase N (APN). This fusion mechanism requires a low $\mathrm{pH}$ (acidic) environment $U$ Virol. 
2009;83(2):712-721). The anti-malarial and anti-autoimmune drug chloroquine is a potential broad-spectrum antiviral drug via increasing the endosomal $\mathrm{pH}$ thus inhibiting virus-cell fusion, interferes with glycosylation of cellular receptors of SARS-CoV-2, and inhibits entry and post-entry viral stages into the cells. Chloroquine also possesses immune-modulating activity, which might enhance its antiviral effect. However, side effects have to be closely monitored especially arrhythmias.

The WHO lunched a global online study called solidarity; (https://www.clinicaltrials.gov/ct2/show/NCT04321616?titles= SOLIDARITY\&draw=2\&rank=1) to compare different regime of antiviral drugs. Drugs considered in this trial:

1. Remdesivir which is developed to combat Ebola and related viruses. It shuts down viral replication by inhibiting a key viral enzyme, the RNA-dependent RNA polymerase and used as an intravenous injection.

2. Chloroquine and hydroxychloroquine which is antimalarial and its use in COVID-19 is still controversial. High near to toxic doses might be needed. It acts as explained before on endosome $\mathrm{pH}$, the virus pre and post entry to the cell and the immune system. Torsade de points might happen as side effect.

3. Ritonavir/Lopinavir (Kaletra) which is anti-HIV combined antivirals, act to inhibit the virus proteases. They used before in SARS-2003 and MERS with ambiguous results and they may cause significant liver damage.

4. Ritonavir/Lopinavir and interferon-beta.

Other drugs used before and acts as RNA Synthesis Inhibitors have been used in SARS-CoV-2003 and MERS-CoV, such as ribavirin, a guanosine analog which has been shown to be ineffective and harmful. Immucillin-A which is a new adenosine, recently developed, inhibits the viral RNA polymerase and of a wide range of anti RNA viruses, including SARS-CoV-2003 and MERS-CoV, and might be useful in the treatment of 2019-nCoV.

The helicases are enzymes allowing double stranded RNA or DNA to separate into single strand then copied to form new viruses. Inhibitors of helicase might be useful in treatment of HCoVs [40]. Another identified broad-spectrum synthetic antiviral potential is RNA synthesis inhibitors [41] and a double-stranded RNA activated caspase oligomerizer (DRACO) which also induces apoptosis of infected cells but spares healthy cells [42]. Another topical antiviral used is $\alpha$-interferon which is produced as a first line im- mune defense against the virus and may be used as an oral spray that was initiated from admission $(8,000 \mathrm{U}$, two sprays, three times a day) that may be given as prophylaxis too (World J Pediatr (2020). https://doi.org/10.1007/s12519-020-00344-6). Guidelines for combination treatment under strict medical supervision been used in different countries. Example of these combined medication according to the clinical status of the patients and for children based on body weight combination of chloroquine phosphate, macrolide (Zithromax) and Lopinavir/Ritonavir [43].

Treatment in children usually modified according to symptoms and doses used are per kilogram body weight. If the patient is asymptomatic with normal blood tests and CXR only needs supportive treatment and monitoring. If the patient showing symptoms of sore throat, fever, nasal congestion, cough, fatigue and myalgia but normal CXR and auscultatory finding, then no treatment needed as before. However, if the patient is in high risk like immunocompromised, chronic lung, liver or renal diseases, asthma, heart failure, congenital heart disease, diabetes, other chronic diseases, and infants less than 1 year old then treatment needed and hydroxychloroquine sulfate may be used for 5 days orally of $6.5 \mathrm{mg}$ per $\mathrm{kg}$ per dose twice in day one (maximum dose $400 \mathrm{mg}$ per dose) than half of that dose from day 2 to day 5 . Zithromax may be added in this stage in a dose of $10 \mathrm{mg}$ per kg per day once per day in day 1 and half that dose for another 4 days. If the child shows CXR changes or oxygen saturation less than $95 \%$ or mild tachypnea or CRP $>100$, $\mathrm{LDH}>245$ then in addition to above antiviral can be added, Lopinavir and or Ritonavir for 7-10 days. Lopinavir in a dose of if the child $<15 \mathrm{~kg}: 12 \mathrm{mg} / \mathrm{kg} /$ dose orally twice daily, for the weight of 15 to $40 \mathrm{~kg}: 10 \mathrm{mg} / \mathrm{kg} /$ dose oral twice daily and for weight of $>40 \mathrm{~kg}$ : $400 \mathrm{mg}$ oral twice daily.

Ritonavir dose is if the child <15 kg: $3 \mathrm{mg} / \mathrm{kg} / \mathrm{dose}$ orally twice daily, for the weight of 15 to $40 \mathrm{~kg}$ : $2.5 \mathrm{mg} / \mathrm{kg} / \mathrm{dose}$ oral twice daily and for weight of $>40 \mathrm{~kg}: 100 \mathrm{mg}$ oral twice daily. Lopinavir and ritonavir should not be used in preterm or full term neonates of less than 14 days old.

In severe cases where the CXR changes $>50 \%$ or oxygen saturation $<90 \%$ in room air or requiring $>4 \mathrm{~L}$ oxygen to maintain saturation $>94$ or severe tachypnea or respiratory alkalosis on blood gas respiratory or metabolic acidosis $\mathrm{PaO}_{2}: \mathrm{FiO}_{2}$ ratio $<300$ or $\mathrm{SpO}_{2}: \mathrm{FiO}_{2}$ ratio < 264, patient require intensive care management however anticipation is better take before reaching to this stage. 
In moderate to severe cases, cases with comorbidities like cystic fibrosis, or fever and hypoxia not subsided by day 3 , or productive cough a broad-spectrum antibiotic have to be considered such as ceftriaxone and vancomycin or based on local guideline and sputum may be taken for culture before antibiotics.

It is not advisable to use high flow nasal cannula oxygen or nebulized medication if other inhalational ways are effective due to air dissemination of the virus. All management should be done in the highest level of isolation available with personal protective equipment (PPE).

There is no conclusive evidence that systemic corticosteroid will benefit stable cases before the development of the ARDS. These steroids may increase the viral shedding and suppress the immune system. Methylprednisolone may be of use when the patients receive ventilation for ARDS [44].

There is no conclusive evidence that ibuprofen or other antiinflammatory factors may worsen the symptoms or complications of the COVID-19, however, there is a possible risk of it may increase the ACE2 receptors which is used for viral cellular entry. Paracetamol should be used as first choice.

Fluid management is crucial as the virus may cause in addition to respiratory and heart failure kidney injury.

There are useful guidance about COVID-19 for pediatric services in the RCPCH website which is regularly up dated; site one: https://www.rcpch.ac.uk/resources/covid-19-guidance-paediatric-services; and site two: https://www.rcpch.ac.uk/sites/default/ files/2020-03/bprs_management_of_children_admitted_to_hospital_with_covid19_-_20200319.pdf

\section{Vaccine against SARS-COV-2}

The world needs collective work and studies to produce an effective and safe vaccine which is the best way to end this tragic pandemic. The aim of vaccination is to prevent infection and reduce disease infectivity and severity. Spike glycoprotein S or its receptor-binding domain (RBD) might be used as an antigen, however, the tendency of CoVs to rapidly mutate and recombine is a potential problem for vaccine development. This has been noticed to enhance the disease post-vaccination in animal models $U$ Infect Dis. 2015;212:1894-1903). Live-attenuated vaccines usually induce a robust and long-lasting cellular and humoral immunity to many different antigens. This may require genomic knockouts or rear- rangement to avoid recombine with wild viruses. There are some animal studies on inactivated vaccines against SARS and MERS CoVs. Despite induction of good cellular and humeral immune response in monkeys there were no effective protection and the immune response itself might induce unwanted dangerous effects (Emerg Microbes Infect. 2018;7:60).

Some studies to develop vaccine from purified antigens combined with adjuvants achieved successful results in animal studies against SARS and MERS. These are mostly developed from subunits like spike glycoprotein S, RBD or nucleocapsid protein. In a study in monkeys, recombinant RBD protein was used to successfully reduce viral loads in lungs and oropharynx and to prevent MERS-CoV pneumonia (EBioMedicine. 2015;2:1438-1446). Other vaccine trials used part of the virus like glycoprotein $\mathrm{S}$ or membrane protein attached to a vector such as an adenovirus. These have been shown good immune response in mouse models and reducing the viral load and morbidity however, not without problems such as pulmonary haemorrhage which might be prevented by adding CD40 ligand to the vaccine. It induced good cellular and humeral immune response, makes this vaccine a promising strategy $U$ Gen Virol. 2005;86(pt 1):211-215) and (Lancet. 2003;362:1895-1896). A vaccine task force recently formed by the UK government, industries and academics from Oxford University (Oxford COVID-19 vaccine trial) [45] to study and try produce a vaccine based on adenovirus vector. Nonetheless, pre-existing immunity against adenovirus might reduce efficacy and this is what this task force will study too. This might be addressed by giving a viral-based vaccine followed by a recombinant vaccine as a booster (Int Microbiol. 2004;7:8394). On the other hand, vaccines given intranasal seems to enhance production of the IgA which provide mucosal protection and reduce viral load in lungs. It is therefore measuring serum antibody response might not be sufficient to assess vaccine efficacy $U$ Gen Virol. 2006;87(pt 3):641-650).

Other vaccine trials such as DNA recombinant vaccine by coding the glycoprotein S or RBD protein are not without significant side effects [46]. Developing a vaccine should be considered as an international mankind priority away from politics or economical gains hence all institutes should collaborate their works and it should be given a priority from the world Health Organization.

\section{Controlling the SARS-CoV-2 spread}

The rapid spread of the CoV-SARS-2 (COVID-19) globally resulted in serious impacts on world health, economy, businesses, 
social, and all other aspects of mankind life. The total effects yet to be reckoned including its post-impact consequences which will be folded out as the situation cleared. The spread of CoV-SARS-2 (COVID-19) is more rapid than SARS 2003 and MERS 2012 hence it highlights the urgent need for rapid, transparent and effective strategies of infection control around the globe as one international strategy. One of the main challenges with CoV-SARS-2 (COVID-19) is the high potential for nosocomial transmission [47]. Health care settings may increase the risk of viral transmission via aerosol-generating procedures like intubation and bronchoscopy. Strict hospital hygiene practices, infection control and effective triage system for suspected patients should aim to prevent nosocomial spread. Patients' isolations ideally in single pressure negative rooms and quarantine contacts should be implemented as early as possible. If not possible a cohort should be applied for patients and health care workers. PPE should be used in suspected or confirmed cases which should include water-resistant gowns, disposable gloves, N95 masks, goggles and face shields. Suction catheters and ventilators with a closed-circuit system and viral filters should only be used. Nebulizers, oxygen masks and nasal continuous positive airway pressure systems should not be used on an open ward. Strict hand hygiene should be applied. Visitors should be avoided or limited to an absolute minimum (J Hosp Infect. 2004;56:215-222). The virus may be carried by up to $3 \%$ of asymptomatic healthcare workers in one study which is an important issue have to be considered in prevention of nosocomial transmission particularly that asymptomatic individuals may have prolonged nasal and throat viral shedding [48].

The virus is inactivated by soap as it will destabilize its lipid layer. HCoVs have been shown to persist for 9 days on dry surfaces and longer on humid surfaces. It can be inactivated by heating to $56^{\circ} \mathrm{C}$ for 30 minutes or by using lipid solvents such as ethanol (> $75 \%$ ), isopropanol (> 70\%), formaldehyde (>0.7\%), povidone-iodine (>0.23\%) and sodium hypochlorite (> 0.21\%) (Med Microbiol Immunol. 2005;194(1-2):1-6).

The degree the virus remained infectious during the incubation period remained uncertain but researches indicates that the viral load in pharynx declined after the first week of infection. Other studies [49] found that the greatest shed for the virus transmission occur 2 - 3 days before symptoms appear.

\section{Conclusion}

The current SARS-CoV-2 pandemic is the third in recent $\mathrm{HCoV}$ infections after SARS-2003 and MERS-2012. Although the source of SARS-CoV-2 is not exactly known but the most acceptable notion is natural recombination that may happen again. The most likely source is bat and pangolin as an intermediate host. More than $80 \%$ of cases recover without complications with a mortality rate approaching $6 \%$. The role of ACE receptors, genetic and HLA antigen, $\mathrm{X}$ chromosome dimorphism, comorbidities, exposure to the common HCoVs, immune reactions and age play vital role in shaping the response and clinical presentation and management. The virus itself may adapt itself to overcome resistance it faced outside its ecological zone by genetic jumps hence there are at least 3 types one ancestors in China and another predominantly in Europe and East Asia. This spill-over phenomenon may lead to jump down when the virus gets attenuated rather than resistant, hence may result in natural herd immunization. Unlike adults and elderly children immune response is more effective in reducing symptoms and mortality, however, sever vasculitis and cytokine storms may happen and cause PIMS and Kawasaki like presentation though fortunately rare. Moreover, children showing more gastrointestinal symptoms Other atypical cases were presented in adults and children that clinicians need to be aware off. There is a possibility that SARSCoV-2 is a neurotropic and cardiotropic virus. Until now there is no specific antiviral treatment against SARS-CoV-2 however different options were tried including antivirals, anti-ACE, immunological, biological, serum, antibodies, stem cells, and supportive management for ARDS. Viral transmission affected by many factors and one of them is its strong nosocomial transmission. These factors and viral shedding and isolation could determine the quarantine period and eradication prevention. There are some vaccinations trials that were discussed in this paper too. The overall consequences of COVID-19 on children and other aspect of life are yet to be determined including psychological impacts, educations, respiratory complications, individual and families welfare, economy, and so many other issues. One important issue that the health authorities and governments should put strategies for future natural or man-made pandemics foreseeing how the health system should be prepared to overcome the scale of problem as and when it suddenly happened. Resources should be kept as a potential for health systems to avoid exhaustion and failure. On the same time during such time other patients should not be ignored or restricted from health services including vaccinations as this may lead to mortality and morbidity 
related to other infectious diseases and or chronic conditions. This may happen when services fully converted to and when lockdown implemented. Moreover, there are positive lesson to be learned such as working from homes and online educations.

\section{Acknowledgment}

To all the frontline health professionals who lost their life to treat this disease.

\section{Disclosure Policy}

The authors declare that there is no conflict of interest regarding the publication of this paper.

\section{Bibliography}

1. Middle East respiratory syndrome coronavirus (MERS-CoV), WHO MERS Global Summary and Assessment of Risk (2020).

2. Susanna KP Lau., et al. "Molecular Epidemiology of Human Coronavirus OC43 Reveals Evolution of Different Genotypes over Time and Recent Emergence of a Novel Genotype due to Natural Recombination". Journal of Virology 85.21 (2011): 11325-11337.

3. New results from research into COVID-19 on mink farms; News item 19-05-2020; Government of Netherlands (2020).

4. Jarvis C., et al. "Impact of physical distance measures on transmission in the UK". Center for Mathematical Modeling of Infectious Diseases (2020).

5. Thevarajan I., et al. "Breadth of concomitant immune responses prior to patient recovery: a case report of non-severe COVID-19". Nature Medicine 26 (2020): 453-455.

6. Russell B., et al. "Associations between immune-suppressive and stimulating drugs and novel COVID-19-a systematic review of current evidence". Ecancer Medical Science 14 (2020): 1022.

7. Wang Y., et al. "Plasticity of mesenchymal stem cells in immunomodulation: pathological and therapeutic implications". Nature Immunology 15 (2014): 1009-1016.

8. De Wit J., et al. "Editorial: Role of HLA and KIR in Viral Infections". Frontiers in Immunology 7 (2016): 286.
9. Guan W-J., et al. "Clinical Characteristics of Coronavirus Disease 2019 in China". The New England Journal of Medicine (2020).

10. W Liu., et al. "Detection of Covid-19 in Children in Early January 2020 in Wuhan China”. New England Journal of Medicine (2020).

11. Shi Y., et al. "COVID-19 infection: the perspectives on immune responses". Cell Death and Differentiation (2020).

12. Ruf B R and Knuf M. "The burden of seasonal and pandemic influenza in infants and children". The European Journal of Pediatrics 137 (2014): 265-276.

13. Van Elden LJ., et al. "Frequent detection of human coronaviruses in clinical specimens from patients with respiratory tract infection by use of a novel real-time reverse-transcriptase polymerase chain reaction". The Journal of Infectious Diseases 189 (2004): 652-657.

14. Hon KL., et al. "Clinical presentations and outcome of severe acute respiratory syndrome in children". Lancet 361 (2003): 1701-1703.

15. Li AM., et al. "Radiological and pulmonary function outcomes of children with SARS". Pediatric Pulmonology 38 (2004): 427 433.

16. Wong SF., et al. "Pregnancy and perinatal outcomes of women with severe acute respiratory syndrome". American Journal of Obstetrics and Gynecology 191 (2004): 292-297.

17. Fagbo SF, et al. "Acute viral respiratory infections among children in MERS-endemic Riyadh, Saudi Arabia, 2012-2013". Journal of Medical Virology 89 (2017): 195-201.

18. Assiri A., et al. "Middle East respiratory syndrome coronavirus infection during pregnancy: a report of 5 cases from Saudi Arabia”. Clinical Infectious Diseases 63 (2016): 951-953.

19. Dong Y., et al. "Epidemiological characteristics of 2143 pediatric patients with 2019 coronavirus disease in China". Pediatrics (2020).

20. Wei Xia MD., et al. "Clinical and CT features in pediatric patients with COVID-19 infection: Different points from adults". Pediatric Pulmonology (2020): 1-6. 
21. Jaillon S., et al. "Sexual dimorphism in innate immunity". Clinical Reviews in Allergy and Immunology 56 (2019): 308-321.

22. Fried JA., et al. "The Variety of Cardiovascular Presentations of COVID-19". Originally (2020).

23. Helms J., et al. "Neurological Features in Sever SARS-CoV-2 Infection". The NEJM (2020).

24. Mao L., et al. "Neurologic Manifestations of Hospitalized Patients With Coronavirus Disease 2019 in Wuhan, China”. The Journal of the American Medical Association Neurology (2020).

25. Munoz AC., et al. "Late-Onset Neonatal Sepsis in a Patient with Covid-19". The New England Journal of Medicine (2020).

26. Baker SC., et al. "Human coronavirus-NL63 infection is not associated with acute Kawasaki disease". Advances in Experimental Medicine and Biology 581 (2006): 523-526.

27. Riphagen S., et al. "Hyperinflammatory shock in children during COVID-19 pandemic". The Lancet (2020).

28. Sam Hassan., et al. "Post-Streptococcal Syndrome in a 5-Years Old Boy with Sever Vitamin D Deficiency Only Responding to Monoclonal Antibody: First Case Report". American Journal of Pediatrics 4.2 (2018): 25-30.

29. Recalcati S. "Cutaneous manifestations in COVID-19: a first perspective". The Journal of the European Academy of Dermatology and Venereology (2020).

30. DeBiasi RL., et al. "Sever COVID-19 in children and Young adults in the Washington, DC Metropolitan Region". The Journal of Pediatrics (2020).

31. Galea S., et al. "The Mental Health Consequences of COVID-19 and Physical Distancing: The Need for Prevention and Early Intervention". The Journal of the American Medical Association Internal Medicine (2020).

32. Van Doremalen., et al. "Aerosol and Surface Stability of SARSCoV-2 as Compared with SARS-CoV-1". The New England Journal of Medicine 382.16 (2020): 1564-1567.

33. Casanova L., et al. "Virus transfer from personal protective equipment to healthcare employees' skin and clothing". Emerging Infectious Diseases 14.8 (2008): 1291-1293.
34. Rivett L., et al. "Screening of healthcare workers for SARS-CoV$\mathrm{S}$ highlights the role of asymptomatic carriage in COVID-19 transmission". ELife (2020).

35. Lytle CD and Sagripanti JL. "Predicted inactivation of viruses of relevance to biodefense by solar radiation". Journal of Virology 79.22 (2005): 14244-14252.

36. Xu Y., et al. "Characteristics of pediatric SARS-CoV-2 infection and potential evidence for persistent fecal viral shedding". $N a$ ture Medicine 26 (2020): 502-505.

37. Rockx B., et al. "Comparative Pathogenesis of COVID-19”. MERS And SARS In A Non-Human Primate Model (2020).

38. Wax RS and Christian MD. "Practical recommendations for critical care and anesthesiology teams caring for novel coronavirus (2019-nCoV) patients". Canadian Journal of Anesthesia/ Journal Canadien D’anesthésie (2020).

39. Shalhoub S., et al. "IFN- $\alpha 2$ a or IFN- $\beta 1$ a in combination with ribavirin to treat Middle East respiratory syndrome coronavirus pneumonia: a retrospective study". Journal of Antimicrobial Chemotherapy 70 (2015): 2129-2132.

40. Adedeji AO., et al. "Evaluation of SSYA10-001 as a replication inhibitor of severe acute respiratory syndrome, mouse hepatitis, and Middle East respiratory syndrome coronaviruses". Antimicrob Agents Chemother 58 (2014): 4894-4898.

41. Lundin A., et al. "Targeting membrane-bound viral RNA synthesis reveals potent inhibition of diverse coronaviruses including the Middle East respiratory syndrome virus". PLOS Pathogens 10 (2014): e1004166.

42. Rider TH., et al. "Broad-spectrum antiviral therapeutics". PLoS One 6 (2011): e22572.

43. https://www.dha.gov.ae/Documents/HRD/Guidelines $\% 20$ for\%20the\%20Management\%20of\%20COVID-19\%20in\%20 Health\%20Facilities\%20.pdf

44. Wu C., et al. "Risk Factors Associated With Acute Respiratory Distress Syndrome and Death in Patients With Coronavirus Disease 2019 Pneumonia in Wuhan, China". JAMA Internal Medicine (2020). 
45. Lane R. "Sarah Gilbert: carving a path towards a COVID-19 vaccine". The Lancet 395.10232 (2020).

46. Addo M. "Safety, tolerability and immunogenicity of vaccine candidate MVA-MERS-S (2018).

47. Zhou Q., et al. "Nosocomial Infections Among Patients with COVID-19, SARS and MERS: A Rapid Review and Meta-Analysis". Med Rxiv (2020).

48. To KK., et al. "Temporal profiles of viral load in posterior oropharyngeal saliva samples and serum antibody responses during infection by SARS-CoV-2: an observational cohort study". The Lancet Infectious Diseases (2020).

49. He X., et al. "Temporal dynamics in viral shedding and transmissibility of COVID-19". Nature Medicine (2020).

\section{Assets from publication with us}

- Prompt Acknowledgement after receiving the article

- Thorough Double blinded peer review

- Rapid Publication

- Issue of Publication Certificate

- High visibility of your Published work

Website: www.actascientific.com/

Submit Article: www.actascientific.com/submission.php

Email us: editor@actascientific.com

Contact us: +919182824667 
